\title{
Some Observations on the Physiology of Cycas-Spermatozoids."
}

By

K. Shibata and K. Miyake.

In the fall of 1905 one of $\mathrm{us}^{2)}$ has, for the first time, observed the living spermatozoids of Cycas revoluta and among others made some experiments on their chemotactic property. The substances used were malic acid, sodium salts of malic and tartaric acids, calcium fumarate and chlorides of potassium and calcium, besides two alkaloid-salts, namely sulphate of atropin and hydro-chloride of chinine. They were used in solutions of various concentrations and the results were always negative: $i$. e. the spermatozoids were found to be quite indifferent towards the chemicals above mentioned.

We are now going to report the results of our further experiments on this subject. The materials were obtained from Kagoshima and Tanegashima in southern Japan. They were sent to Tokyo at the end of September and early in October. The well known capillary method was used and the capillary tube filled with experimenting solution was applied to each freely swimming spermatozoid. In these experiments we paid special attention to the constituents of the outside medium, i. e. the solution in which the spermatozoids are swimming. For we know from the recent studies of Shibata ${ }^{3)}$ on the spermatozoids of Pteridophyta and of $\mathrm{KNIEP}^{4)}$ on Bacteria that the chemotactic reaction is considerably influenced by the nature of the outside medium.

1) Read before the Tokyo Botanical Society, Oct. 27th, 1906.

2) Miyake, Ber. d. Deutschen Bot. Gesellsch., Bd. XXIV. 1906. Also in Bot. Mag. Tokyo, Vol. XIX. Oct. 1905.

3) Jahrb. f. wissensch. Bot, Bd. XLI, 1905.

4) Jahrb. f. wissensch. Bot., Bd. XLIII, 1906. 
The solutions used as outside media are as follows :

${ }^{3} / 10$ mol. solution of cane sugar $+{ }^{1} / 1000 \mathrm{~mol} \mathrm{H}_{2} \mathrm{SO}_{4}$

$3 / 10$ mol. solution of cane sugar

$1 / 2$ mol. solution of dextrose $+{ }^{1} / 1000$ mol. $\mathrm{H}_{2} \mathrm{SO}_{4}$

$1 / 2$ mol. solution of dextrose

$1 / 2$ mol. solution of levulose $+1 / 1000 \mathrm{~mol}^{1} \mathrm{H}_{2} \mathrm{SO}_{4}$

$1 / 2$ mol. solution of levulose

$2 / 10$ mol. solution of KNO

$2 / 10$ mol. solution of Asparagin

The capillary solutions tried are:1)

$1 / 50$ mol. solution of sodium malate

$1 / 50$ mol. solution of sodium maleinate

$1 / 50$ mol. solution of calcium maleinate

$1 / 50$ mol. solution of ammonium fumarate

$1 / 50$ mol. solution of ammonium succinate

$1 / 50$ mol. solution of patassium citrate

$1 / 50$ mol. solution of ammonium asparaginate

$2 / 10$ mol. solution of dextrose

$2 / 10$ mol. solution of levulose

$3 / 10$ mol. solution of cane sugar

${ }^{1} / \overline{5} 0$ mol. solution of chinine hydro-chloride

$1 / 10$ mol. solution of ephedrin hydro-chloride

Concentrated solution of egg-albumin

Archegonial contents of Cycas. ${ }^{2)}$

We tried the various combinations of the above mentioned solutions, and in not one case have been able to observe either positive or negative chemotactic reaction. It is especially to be noticed that the spermatozoids have shown no reaction towards the archegonial contents. On the other hand we have observed that some Pteridophyta-spermatozoids are attracted by the archegonial contents of Cycas. The following experiments were made with the spermatozoids of Equisetum:

1) Into the capillary solutions we added usually cane sugar or other substances which were used for outside media, in about the same concentration as the latter, to avoid the difference of osmotic pressure of two solutions.

2) Thick, mucilaginous fluid of the egg as well as more clear watery fluid of the neck-cells. 


\section{EXPERIMENT I.}

\{Capillary solution: archegonial contents of Cycas.

\{ Outside solution: water.

Reaction very distinct: strong attraction towards the mouth of the capillary tube; at first some indication of repulsion, later entering into the tube, continuing the activity in the capillary fluid for at least 30 minutes.

\section{EXPERIMENT II.}

Capillary solution: same as the preceding.

Outside solution: ${ }^{1} / 200$ mol. solution of $\mathrm{Ca}\left(\mathrm{NO}_{3}\right)_{2}$

Reaction very distinct: nearly all spermatozoids being attracted towards the mouth of the capillary tube; moving inside the tube for more than 30 minutes.

\section{EXPERIMENT III.}

Capillary solution: same as above.

Outside solution: ${ }^{1 / 10}$ mol. solution of sodium malate.

No reaction whatever.

Now we see in the above experiments that the Equisetumspermatozoids are attracted by the archegonial contents of Cycas and the chemotactic reaction is not least iufluenced when the outside medium contains calcium salt, while the attraction disappears by the presence of malic acid salt in the medium. It is therefore highly probable that the chemotactic attraction is due to the presence of malic acid in the archegonium.

From these results we have to conclude that either the Cycas-spermatozoids lack the chemotactic irritability or the chemotaxis can only take place under some unknown external conditions such as the special composition of outside medium. If the former alternative is found to be correct, the spermatozoids have probably lost the chemotactic irritability which has existed in the ancester of Cycas and perform, at present, the act of fertilization by means of mechanical or some other contrivances. The second alternative seems not to be very probable although we are yet far from expressing any definite opinion about it as we do not yet know the chemical constituents of the natural fluids in which the spermatozoids swim in the archegonial chamber before they penetrate into the egg. 
Former investigators of the spermatozoids of cycads ${ }^{1)}$ have usually used $10 \%$ cane sugar solution (about $3 / 10$ mol. solution) for outside medium with good results. The osmotic pressure of the solution probably corresponds nearly to the turgor of the spermatozoid-body. In our experiments this solution was also used quite frequently. Then $1 / 2$ mol. solutions of cane sugar, dextrose and levulose were tried and the spermatozoids were found to behave just like as in $3 / 10$ mol. cane sugar solution. 1 mol. solutions of cane sugar and dextrose (osmotic pressure $\left.=\left[22,4+\frac{t^{\circ}}{273} \mathrm{~atm}.\right]\right)$ were also tried. In these cases the spermatozoids have contracted their bodies by the loss of water and stopped the motion for a short time. Very soon the spermatozoids recover from temporary inactivity and in a few minutes they continue the motion as actively as before. In one case we observed that one of the spermatozoids in 1 mol. solution of dextrose was in motion for nearly five hours. This remarkable behavior of Cycas-spermatozoids in concentrated solutions of sugar is due to the permeability of the plasma membrane for cane sugar and dextrose. We know by the studies of OVERTON and others that sugars, higher alcohols and amidoacids are almost impenetrable into the plasma membrane of ordinary plant cells. So that such cells undergo permanent plasmolysis in the highly concentrated solution (hyperosmotic solution) of the substances above mentioned. One of us has also observed the similar abnormal permeability of plasma membrane in Isoctes-spermatozoids. ${ }^{2}$ Hexoses (dextrose, levulose etc.) were found to penetrate easily the living plasma membrane of the spermatozoids. This remarkable deviation of the behavior of the spermatozoids in regard to the permeability of the plasma membrane is very interesting from physiological as well as biological standpoints and deserves further investigation.

In conclusion, we wish to express our sincere thanks to Profs. IWASAKI and IKEDA of Kagoshima, Mr. HANIU of Tanegashima and Prof. FujII of Tokyo for the help in securing the material. Imperial University, Tokyo.

1) Webber, Bulletin No. 2 Bureau of Plant Industry, U. S. Dept. Agr., 1901. P. 54. Mirake, Ber. d. Deutschen. Bot. Gesellsch., Bd. XXIV, 1906, P. 81.

2) SHIBATA, l. c. p. 594 . 